This item was submitted to Loughborough's Research Repository by the author.

Items in Figshare are protected by copyright, with all rights reserved, unless otherwise indicated.

\title{
Dynamics of control in construction project teams
}

PLEASE CITE THE PUBLISHED VERSION

http://dx.doi.org/10.1080/01446190903365657

PUBLISHER

Routledge (@ Taylor \& Francis)

VERSION

AM (Accepted Manuscript)

LICENCE

CC BY-NC-ND 4.0

\section{REPOSITORY RECORD}

Tuuli, Martin Morgan, Steve Rowlinson, and Tas Yong Koh. 2019. "Dynamics of Control in Construction Project Teams". figshare. https://hdl.handle.net/2134/6656. 
This item was submitted to Loughborough's Institutional Repository (https://dspace.lboro.ac.uk/) by the author and is made available under the following Creative Commons Licence conditions.

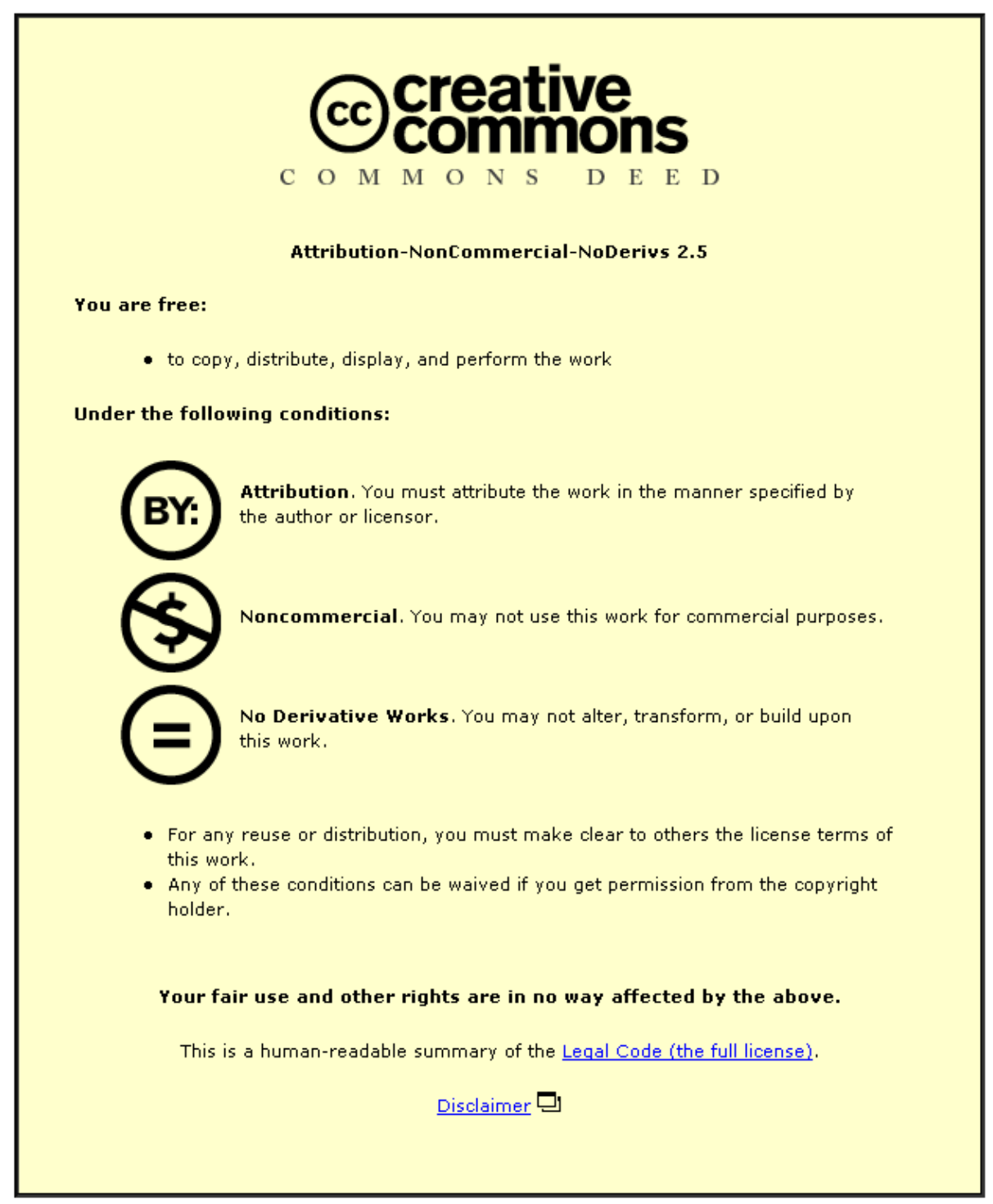

For the full text of this licence, please go to: http://creativecommons.org/licenses/by-nc-nd/2.5/ 


\section{DYNAMICS OF CONTROL IN CONSTRUCTION}

\section{PROJECT TEAMS}

MARTIN MORGAN TUULI ${ }^{1}$, STEVE ROWLINSON ${ }^{2}$ and TAS YONG $\mathrm{KOH}^{2}$

${ }^{1}$ Department of Property and Construction, University of Westminster, London, UK

${ }^{2}$ Department of Real Estate and Construction, University of Hong Kong, Hong Kong

Abstract: Control is pervasive in construction project environments. The management of projects through various planning and control tools has therefore been described essentially as rebureaucratization which increases control over individuals, teams and organizations through ideologies of efficiency and performativity. Yet, certain characteristics of the project setting make it an ideal climate for the empowerment of individuals and teams. The manifestations of control in five construction project management teams involved in two ongoing construction projects in Hong Kong are examined. The interpretive and exploratory focus of the study favoured the use of a qualitative research design and the case study approach in particular. Control is viewed as all devices and systems employed to ensure that acts, behaviours, outcomes and decisions of individuals, teams and organizations are consistent with meeting organizational or project goals, objectives and strategies. The findings indicate that a portfolio of control modes is implemented in project teams comprising both formal (i.e. behaviour- and outcome-based) and informal (i.e. clan- and self-based) control mechanisms which are not necessarily incompatible. While formal control remains the primary control mode, a portfolio of control appears necessary to augment the inadequacies of formal control due to the evolving nature of the project environment.

Keywords: empowerment, formal control, Hong Kong, informal control, portfolio of control 


\section{INTRODUCTION}

Empowerment represents a moral hazard dilemma for managers who grapple to reconcile the potential inherent loss of control with the fundamental organizational need for goal congruence (Mills and Ungson, 2003). Empowerment initiatives have therefore often failed to achieve the intended positive results because of management's reluctance to give up control (c.f. Mills and Ungson, 2003, Simons, 1995, Argyris, 1998, Dewettinck and Buyens, 2006). In the project context, some have argued that the management of projects through various planning and control tools is essentially rebureaucratization (Hodgson, 2004) which increases control over individuals, teams and organizations through ideologies of efficiency and performativity (Fournier and Grey, 2000). This is perceived as aspiring a new form of “iron cage” of project rationality (Cicmil and Hodgson, 2006). Contrary to this view, the site-based nature of projects characterised by complexity, uncertainty, poor communication (i.e. timing, extent and content), inadequate co-ordination (i.e. of organisations and activities) and inadequate integration (i.e. of tasks, organisations

and personnel) provides an ideal climate for the empowerment of individuals and teams.

Control is therefore often viewed as incommensurate with empowerment which emphasizes the expansion of employee autonomy and responsibility through the removal of control-oriented management approaches to create a work environment that permits employees to apply their full potential in the performance of tasks. However, recent empirical developments in the organizational and management literature actually depict empowerment as a form of control. In particular, 
empowerment is shown to manifest as self-control (c.f. Leifer and Mills, 1996, Kirsch, 1996, Kirsch, 1997) which is not necessarily incompatible with other forms of control as some have surmised. This study therefore set out to explore the manifestation of control in construction project teams, by examining the extent to which a portfolio of control modes exists and how such control is exercised. In the sections that follow, a framework of control modes is advanced that incorporates empowerment as selfcontrol. The research design is subsequently outlined and the findings from the analysis of manifestations of control in five construction project management teams involved in two ongoing construction projects presented and discussed. Conclusions are drawn and implications for theory and practice outlined.

\section{DEVELOPMENT OF A CONTROL FRAMEWORK}

The organization and management literature views control as encompassing all the devices and systems employed to ensure that the behaviour and decisions of organizational constituents are consistent with the organization's goals, objectives and strategies (Merchant and Stede, 2007, Flamholtz et al., 1985). A prominent organizing framework for the mechanisms (i.e. devices and systems) through which organizational control is exercised is Ouchi's (1979) three control modes/types model, comprising market control, bureaucratic control and clan control. In the market control mode, premium is placed on the ability to precisely measure and reward individual contributors to a task as the means of control. Bureaucratic control relies on surveillance and close evaluation, built on the comparison of outcomes or behaviours with predetermined ones. Clan control relies on informal socialization, such as shared values, beliefs and norms, to eliminate goal incongruence. 
Kirsch (1996), however, argued that Ouchi’s (1979) framework is incomplete when applied to complex and nonroutine tasks (e.g. construction projects) as it fails to account for 'knowledge of task' as a key determinant of type of control. Consequently, Kirsch (1996) dismissed market control as an inappropriate control mode in complex tasks contexts and proposed instead the addition of self-control, an appropriate mode of control when knowledge of task is high. This view resonates with the notion that construction is knowledge- and a professional-based industry, a characteristic which makes the project setting a suitable climate for empowerment (c.f. Dainty et al., 2002, Greasley et al., 2005, Walker, 2002). Kirsch (1996) described self-control as the scenario where one sets his/her own targets in relation to the needs of the organization or task, monitors his/her own behaviours and when necessary changes them in accordance with the self-set or agreed targets. Outcomebased and behaviour-based controls, the two modes of bureaucratic control, are viewed as formal controls which attempt to restrict behaviours or outcomes while clan and self-control depict informal control modes which attempt to induce a value or belief change (Flamholtz et al., 1985).

Table 1 summarizes the key characteristics of the four modes of control, as adapted from Nieminen and Lehtonen (2008) with additional information from prior studies (e.g. Eisenhardt, 1985, Kirsch, 1996, Kirsch, 1997, Leifer and Mills, 1996, Ouchi, 1979, Sharma, 1997), and provides an organizing framework for studying control in project teams. Control in this context is viewed as encompassing all the devices and systems employed to ensure that acts, behaviours, outcomes and decisions of individuals, teams and organizations in project are consistent with meeting organizational or project goals, objectives and strategies (c.f. Merchant and Stede, 2007, Flamholtz et al., 1985, Nieminen and Lehtonen, 2008). Control viewed in this 
manner, can be examined from different levels within the project context; the interorganization and the intra-organization levels. Interpolating an agency theory perspective (c.f. Eisenhardt, 1985) into the construction project context, attempts by the principal (i.e. client) to control the agent (i.e. contractors and consultants) is particularly pervasive. Controls that arise from this principal-agent relationship at the inter-organizational level often translate at the intra-organization level between top managers and the individuals and teams they deploy at the project-level and can often be a direct reaction to the inter-organization level controls.

INSERT TABLE 1 HERE

\section{RESEARCH DESIGN AND METHODOLOGY}

\section{Design of the Study and Data Collection}

This study has an interpretive and exploratory focus as it seeks to examine how control manifests. Such a focus favours the use of a qualitative research design and the case study approach was particularly appropriate as it encompasses the holistic, indepth study of a phenomenon using a variety of data sources and procedures (Yin, 2003). Case studies are most useful when the boundaries between phenomenon and context are not clearly evident as in the examination of the manifestations of control in this case. Two cases were selected for study; an infrastructure project (i.e. Project Alpha) and a building project (i.e. Project Beta). While the projects are comparable in some respects (e.g. construction methods employed i.e. high use of precast, government departments as client, design-bid-build element of their procurement, etc.), consistent with an attempt at literal replication (c.f. Yin, 2003), they also differ in two key criteria; project lifecycle at start of case study and the project delivery/procurement system in use. These two characteristics have been shown to 
induce substantial variation in the authority, control and responsibility structures within the multi-organizational project environment (c.f. Bryman et al., 1987, Newcombe, 1996, Rowlinson et al., 1993, Walker, 2002). The two projects therefore provided consistent, differentiated and ambiguous information rich settings for study that allowed the emergence and interplay of various other contextual factors. While the two projects were the primary focus of the study, the units of analysis were the five embedded project management teams of the contracting parties in the projects.

Three data collection techniques were employed; documentary data analyses, observations and interviews. Documentary analysis was used to gain a deeper understanding of the projects and to identify project specific issues with control implications. Passive observations were undertaken at project meetings and site visits to capture authority, responsibility and control related issues in an emergent and emic manner. Indeed, Mangham (1986) asserts that the use of managerial language can reveal a number of aspects of power and control in ways which are rarely made explicit in other forms within organizations. The interviews elicited information about manifestations (incidents) of control (covering the range of control modes as discussed and presented in Table 1). A key component of the interviews was identifying the goals of key stakeholders and eliciting information on control mechanisms linked to the achievement of such goals. This was in recognition of purposive or goal directed nature of control (c.f. Kirsch, 1997). The Critical Incident Technique (c.f. Flanagan, 1954) was used to encourage respondents to recall control episodes on the project and to describe them in as much detail as possible. A total of 30 semi-structured face-to-face interviews were conducted with team members (17 on Project Alpha and 13 on Project Beta), carefully selected on the basis of their critical roles as either controllers or controlees. The interviewees role descriptions on the 
projects included project manager, site agent, quantity surveyor, quality control manager, project architect, resident engineer, project clerk of works, etc. All but one interview were tape recorded and transcribed verbatim. One respondent in Project Alpha Client's team declined to have the interview with him recorded, in which case only notes were taken. By employing three different data sources, convergence of information was achieved through triangulation. In particular, inconsistencies in information from one source (e.g. interviews) were clarified using data from the other sources (e.g. documentary analysis or observations). Thus, collaborative evidence on pertinent issues were obtained from multiple sources to assert their credibility.

\section{Background of Projects and Teams}

Project Alpha

The project is an integral part of a $7.6 \mathrm{~km}$ long major highway infrastructure undertaking. The works comprise the construction of a $1.1 \mathrm{~km}$ elevated viaduct, dual three-lane carriageway (average $65 \mathrm{~m}$ above ground) to connect a tunnel (under construction) on one end and a cable-stayed bridge (under construction) at the other end. The project is delivered under a traditional design-bid-build approach with a noncontractual partnering arrangement in place. The contract is a re-measurement type with a price fluctuation clause and awarded for an initial contract period of 40 months and at an initial contract sum of HK\$1,012 million. There are three primary project management teams; the client's team (i.e. Client-Alpha), the consultant's team (i.e. Consul-Alpha) and the contractor's team (i.e. Contra-Alpha). The study of Project Alpha began about a year after the project started and lasted 30 months.

The client (i.e. Client-Alpha's parent organization) is a government department with responsibility for the planning, design, construction and maintenance of the public 
road system and railway networks with an average annual budget of about HK\$4.6 billion. A team of 5 is assembled in-house to coordinate the client's input into the project. The consulting engineer (i.e. Consul-Alpha's parent organization) is a Hong Kong-based international engineering consulting firm with more than 60 years experience in the delivery of projects in the fields of building, civil engineering and industrial construction. Consul-Alpha team comprises The Engineer (i.e. responsible for design and overall contract administration) and a team of Resident Site Staff (RSS, i.e. responsible for site supervision). The contractor (i.e. Contra-Alpha's parent company) is a joint venture between two Hong Kong-based French sister companies and a Chinese state-owned company. The companies brought together their enormous international expertise and local experience to forge a partnership. As part of the joint venture agreement, a Project Joint Venture Board was in place to oversee and provide the strategic direction for the effective delivery of the project.

\section{Project Beta}

The project is Phase 4 (of six phases) of a public-rental housing programme involving the construction of three 41-storey blocks, estimated to provide a total of about 2,300 units of rental apartments. The value of the works is estimated at about HK\$434 million and is contracted out for an initial period of 36 months. The works are procured broadly under a traditional design-bid-build approach with a non-contractual partnering arrangement in place. Special conditions of contract cater for six work packages contracted under a Modified Guaranteed Maximum Price (MGMP) arrangement which collectively make-up about $31 \%$ of the contract sum. The study began slightly more than a year after the project started, and lasted 15 months. There are two primary project management teams in the project; the client's team (i.e. DualBeta) and the contractor's team (i.e. Contra-Beta). 
The client (i.e. Dual-Beta Team parent organization) is a statutory body that develops and implements the government's public housing programme. As a departure from previous practice, the development and procurement sub-division which mainly undertakes R \& D related roles was chosen to implement the project, instead of one of the traditional project sub-divisions. The functional heads within the matrix design of the client's organization nominated members to form the core project management team (i.e. Dual-Beta team). A site team was also put in place to undertake direct site supervision. The teams played a dual role as both consultant and client, responding to design issues and making the approvals often reserved for the client's team in a traditional project set-up. The contractor (i.e. Contra-Beta's parent company) is part of a diversified conglomerate and plays a leading role in property development, construction and materials supply. Their choice as contractor for Project Beta was an assertion of their role as one of the leading contractors in the public housing market with a reputation of excellence and quality in housing delivery.

\section{Data Analysis}

\section{Analysis Strategy}

The data analyses followed Woolsey's (1986) three-step guide for analyzing critical incident data. The first step was descriptive in nature, where all the information about a potential control mechanism was collated from the transcripts of interviews and the notes from the documentary analysis and passive observations. At this stage, inconsistencies in information from one source where resolved by double checking with that obtained from other sources to achieve convergence (as per the central tenet of triangulation). The identification of potential control mechanisms was facilitated by drawing on Kirsch’s (1997) criteria that control mechanisms are devices or systems that identify/specify or evaluate acceptable behaviours or outcomes of a controlee (i.e. 
individual, team or organization). In a second step, a descriptive label was applied to the detailed descriptions of the potential control mechanisms. The final step was the classification of the identified control mechanisms into the control modes framework outlined in Table 1. Thus, this stage of the data analysis followed the 'framework analysis’ approach (c.f. Ritchie and Spencer, 1993) which facilitated the ordering and sorting of the mechanisms into the a priori framework in Table 1 . The classification of the identified control mechanisms was on the basis of their nature, initiator, documentation status and evaluator as depicted in Table 2 in accordance with the work of Kirsch (1997) and Jaworski (1988). For example, if a mechanism specified or identified behaviours for the controlee (i.e. agent e.g. individual, team or organization) to engage in and was initiated by the controlee's management or an external entity (i.e. principal) and formally documented, then such a mechanism was classified as a behaviour-based.

\section{Credibility and Trustworthiness Measures}

Credibility and trustworthiness are key issues in qualitative research and in case studies in particular. Demonstrating credibility and trustworthiness in the design and execution of qualitative research is particularly important in establishing confidence in the findings and conclusions drawn. Several measures were taken in the case studies and were mainly based on the recommendations of Butterfield et al. (2005);

- Triangulation in the data collection: three sources of data were relied upon in each case study; documentary, observations and interviews. This enabled verification of emergent issues from multiple sources to achieve convergence.

- Descriptive validity was ensured by working with verbatim transcripts of interviews, photocopied documentary evidence and notes and direct quotations as much as possible from the observations.

- Interview fidelity was achieved through consistent application of the interview protocol but also probing as much as possible to discover the different perspectives of the interviewees. 
- Theoretical validity: This measure is demonstrated in the discussion of the case study findings, in a subsequent section, by reference to previous research to show how the emergent themes from the cases are consistent or inconsistent. The aim therefore is to demonstrate theoretical agreement and convergence with previous work.

INSERT TABLE 2 HERE

\section{FINDINGS}

\section{Control Dynamics in Project Alpha}

Client-Alpha Team

The manifestations of control in Client-Alpha team were classified into the four control modes framework developed earlier. Due to space constraints, only excerpts of the matrix of the identified control mechanisms are presented in Table 3. The full matrix is reported in Tuuli (2009). The full lists of control mechanisms are, however, depicted in Tables 4, 5, 6 and 7. Interestingly, there is no manifestation of self-control in the Client-Alpha team. As a team from a government department, this is hardly surprising. Indeed, some of the Client-Alpha team members were described by colleagues in the Consul-Alpha and Contra-Alpha teams as seemingly uninterested in the project itself. Preferring a "quiet life" of no problems, no mistakes, issue free project and nice project reports. Such an apathetic attitude can therefore not promote proactivity which is an important ingredient for self-control to manifest. Behaviourbased controls are primarily of surveillance nature (e.g. complaint walk, Electronic Document Management System, etc.) while others seek to achieve conformance by specifying acceptable behaviours or expected acts (e.g. contract and Project 
Administration Handbook). Outcome-based controls are exercised through mechanisms that specify limits or standards that are then monitored (e.g. approval limits on variation orders and project budget). Clan control mechanisms are shaped around the socialization of individuals, so as to create an environment in which individuals identify with collective goals, norms or values (e.g. mutual objectives and mission statement).

\section{Consul-Alpha Team}

As in Client-Alpha, behaviour-based controls in Consul-Alpha are exercised primarily as surveillance (e.g. site diary, Technical Audits, etc.) and conformance (e.g. role specification, RSS Manual, etc.) mechanisms. The outcome-based and clan controls identified in Client-Alpha are also exercised in Consul-Alpha. Unlike in Client-Alpha, however, self-control manifests in Consul-Alpha mainly in the form of proactive acts aimed at improving personal reporting and record keeping (e.g. weekly report, secondary filling system and tick-box checklist) as well as altruistic acts (e.g. volunteer training).

\section{Contra-Alpha Team}

Behaviour-based controls in Contra-Alpha team manifest primarily as surveillance mechanisms (e.g. independent checkers, reporting, programmes, etc.), conformance systems (e.g. progress meetings, consultant, operating guidelines, etc.) and guarantee mechanisms (e.g. insurance strategies, quality assurance, etc.). Outcome-based controls are exercised through mechanisms that are used to monitor the achievement of limits or standards (e.g. specifications, substandard work audits, etc.), targets (e.g. key dates, project budget, etc.) and guarantees to ensure the achievement of targets or 
standards or remedies paid in lieu (e.g. retention fund, liquidated damages, etc.). As in both Client-Alpha and Consul-Alpha teams, clan controls in Contra-Alpha comprise socialization interventions. However, here the socialization interventions were of 2 kinds; those aimed at aligning goals, norms and values across the organizations in the project team (e.g. partnering, joint problem solving, informal events, etc.) and those aimed at aligning goals, norms and values within the organization (e.g. goal alignment, identity orientation, etc.). The latter were particularly important since Contra-Alpha is a joint venture, in which members from the different partners may still identify with their parent organization with the potential for self interest. Selfcontrol manifested as proactive use of alternative construction methods in which the contractor continuously searched for innovative methods of executing the works which are safer, more cost effective and less time consuming.

\section{INSERT TABLE 3 HERE}

\section{Control Dynamics in Project Beta}

\section{Dual-Beta Team}

There were manifestations of all four modes of control in the Dual-Beta team. Behaviour-based controls are exercised through the structuring of systems and processes for effective monitoring or surveillance. The contract is used as the overall governance framework for relationships and responsibilities among the parties. This is supplemented with a structured dispute resolution system to mitigate disputes at source. Meetings, reporting and standard operating procedures are then used to monitor behaviours and actions as well as to achieve conformance. Outcome-based control manifests in the form of annual performance appraisals, whereby the performance of each team member is evaluated against pre-specified performance 
standards. The specifications provide the standard for the quality of materials and level of workmanship expected. A project budget also provides a means of controlling expenditure on the project. Clan control mechanisms in Dual-Beta team include noncontractual partnering, public pressure and rule following culture, which are exercised mainly through socialization processes that reinforce a sense of shared norms, values and goals. Self-control mechanisms also manifests as proactive acts in response to changes in project circumstances. For example, design development workshops are instituted by the project architect in response to lengthy delays in design approvals, while revision of specifications is a measure to minimize spill over delays from changes in construction sequence.

\section{Contra-Beta Team}

All four modes of control also manifested in Contra-Beta. Behaviour control mechanisms are shaped around the structuring of systems and processes, so as to effectively monitor enacted behaviours (e.g. safety audits, wage protection schemes, etc.). Several outcome-based controls are also employed mainly to maintain standards (e.g. specifications, Independent Checking Unit, etc.), meet desired performance targets (e.g. mop-up, cost plan, etc.) and for quality assurance (e.g. preferential tendering, defects liability period, etc.). Several clan control mechanisms are also in place, shaped around socialization processes (e.g. partnering, corporate mission, etc.) and peer/public influence (e.g. peer recognition, public pressure, etc.). Similarly, self-control mechanisms are shaped around two themes; proactive attitude in reaction to different or changing project circumstances (e.g. sequencing of construction works, MGMP packages, etc.) and the contractor's strong desire to be an industry leader (e.g. CSR programme, etc.). 


\section{Cross-Team Analysis of Control Mechanisms}

\section{Behaviour-based Control Mechanisms}

Table 4 summarizes the behaviour-based control mechanisms in the teams across the two projects. Monthly progress/site meeting and contract are used in all the teams. This is not surprising as contracts provide the primary framework for shaping the relationships and responsibilities of individuals and teams in projects while meetings provide an environment to continually re-enact such relationships and roles. Several mechanisms are also used in teams in both projects and these mechanisms are primarily built around reporting on different aspects of the project (e.g. monthly progress/site meetings, reports, etc.), surveillance of enacted behaviours (e.g. consultant/site supervision team, project programme, etc.) and guarantees for performance (e.g. insurance strategies, quality assurance systems, etc.). Behaviourbased control mechanisms are mainly team specific; and predominantly specific to teams in Project Alpha than teams in Project Beta. These team specific control mechanisms appear to be in response to peculiar project and team circumstances (e.g. MGMP, joint venture, project complexity, etc.). Behaviour-based controls are also used most in contractor teams than in client or consultant teams. From an agency theory perspective, this is less surprising as potential controllers of contractors or their teams can emerge from many sources including; her own organization's team, project team, her organization's head office, consultant, client and other external entities.

\section{INSERT TABLE 4 HERE}

\section{Outcome-based Control Mechanisms}

The comparison of the outcome-based controls across the teams in the two projects is shown in Table 5. As in behaviour-based control, contractor teams experience far 
more outcome-based control than client and consultant teams. Annual performance appraisal and project budget are used in all the five teams. Team specific mechanisms are exercised only in Contra-Beta team and are attributable mainly to the MGMP arrangement. Several mechanisms span teams in both cases. However, there are differences in the way some of the common mechanisms are exercised. For example, in Contra-Alpha priced bills of quantities covered all work sections while in ContraBeta only non-GMP works have priced bills of quantities. The MGMP packages are estimated and valued on an "open book accounting" mechanism. The maintenance/defects liability period in the two cases also committed the contractors differently. While Contra-Alpha is committed to rectifying defects of up to 1 year from substantial completion, Contra-Beta is committed for up to 2 years for all works and 10 years for structural related works.

\section{INSERT TABLE 5 HERE}

\section{Clan Control Mechanisms}

As in behaviour- and outcome-based controls above, clan controls are dominant in contractor teams compared with that in client and consultant teams (see Table 6). Non-contractual partnering with a partnering charter/mutual objectives and joint problem solving are used as control mechanisms in all teams. Team specific clan controls manifest and are directly linked to peculiar project and team circumstances. Several mechanisms are also exercised in teams across the two cases in a very similar manner. For example, similar informal events aimed at promoting socialization through interaction are evident in teams across both cases (e.g. barbecues, dinner, etc.). The two contractor teams also target similar industry awards and recognitions (e.g. considerate contractor award). There are, however, project specific mechanisms 
spanning only teams in the respective projects (i.e. joint problem solving and nationality \& culture in Project Alpha; and public pressure and team spirit in Project Beta). The mechanisms in Project Beta are a response to a commitment to achieve win-win outcomes for all parties while those in Project Alpha are a consequence of the multicultural teams assembled (i.e. both within and across organizations) and the publicity the project has received due to the innovative arrangements and its experimental status.

\section{INSERT TABLE 6 HERE}

\section{Self-Control Mechanisms}

Table 7 depicts the self-control mechanisms across the 5 teams in the two projects. In accordance with the "rule following culture" that is evident in typically bureaucratic culture in government departments, no self-control mechanism manifests in ClientAlpha team. It is apparent that both the organization culture and the apathetic mindset of some of the Client-Alpha team members are not supportive of self-control. Alternative construction methods/sequence of works is the only self-control mechanism common to the contractor teams across the two projects. This is hardly surprising as contractors normally have the flexibility and responsibility in deciding the best ways to execute the works on site. In both projects, such proactive changes in methods resulted in the works being undertaken more safely, faster and in a more cost effective manner. As Table 7 indicates, self-control mechanisms are predominantly team specific. In Contra-Beta in particular, the self-control mechanisms are a direct result of the built in flexibility in the procurement arrangement (i.e. MGMP). This ensured the contractor's involvement in the design process and made it possible for the contractor to also try out some of her initiatives (e.g. CSR and R \& D). Unlike 
Client-Alpha where self-control was not evident, Dual-Beta team had a proactive attitude. A plausible explanation for the differences in the two teams even though they are both from government departments stems from the division of the client's organization that Dual-Beta team originates and the fact that the team plays a dual role as client and designer. As the R \& D section, the Development and Procurement Subdivision has been in the forefront of the client's innovative initiatives, some of which are actually being tested in Project Beta. A culture of proactivity seems to have been built into the way things are done which spurs a desire to succeed. Self-control therefore requires cultivation and appears to flourish in an organizational environment that is supportive.

\section{INSERT TABLE 7 HERE}

\section{DISCUSSION}

The manifestations of control in construction project management teams were investigated by drawing on recent developments in management and organizational control theory. The findings confirm that a portfolio of control modes is implemented in project teams which include a combination of formal (i.e. behaviour- and outcomebased) and informal (i.e. clan- and self-control) modes of control. The finding of a portfolio of control modes in this study is consistent with the extant case study findings (c.f. Badenfelt, 2007, Kirsch, 1997, Langfield-Smith, 2008, Nieminen and Lehtonen, 2008). A portfolio of control modes appears necessary in projects because formal modes of control are static in nature, as they tend to be built into the contract or agreements at the beginning of the projects and are often difficult or impossible to amend thereafter. Consequently, formal control can prove inadequate in dealing fully with the evolving nature of the project environment in which plans, targets and 
procedures are often not immutable but fluid and changeable. Formal controls can particularly become redundant when controllers are inexperienced or lack projectrelated knowledge. For example, in Project Alpha the inexperience of the RSS in precast segmental viaduct construction and the use of the new generation launching girder meant that the RSS could not adequately check method statements and temporary work designs regarding the bridge construction. In Project Beta, the inexperience of the Independent Checking Unit in gabion wall design and construction led to considerable delay in granting approval to the contractor's proposed design.

The reactions to the two incidents of inexperience in the projects, however, illustrate two response modes often employed to address inadequacies in formal control modes. Controllers either design new formal control mechanisms or implement other control mechanisms to help in implementing the formal controls already in place. Alternatively, controllers invoke informal control modes which are more responsive to changing project conditions (see Table 1). In Project Alpha, the RSS tended to place much weight on the Independent Checking Engineer and the Check Certificates as a basis of either rejecting or approving the contractor's designs. A combination of these formal modes ensured the effective control of the contractor. In project Beta, however, the Project Architect invoked self-control (i.e. informal control) in the form of Design Development Workshops to help iron out differences before proposed designs were submitted to the ICU. Evidently, it appears that there is no exclusive use of formal or informal controls in project teams, but a complementary application of both, although the primary control mode remains bureaucratic/formal control (c.f. Hodgson, 2002, Nieminen and Lehtonen, 2008). But how self-control thrives in the midst of so many behaviour-based, outcome-based and clan controls, however, is not easily explained. A plausible explanation is that project participants view formal control mechanisms as 
a necessary evil. As Adler and Borys (1996) argue, bureaucracy is not always coercive but can also be enabling. In support, Nieminen and Lehtonen (2008) recently found that some bureaucratic control mechanisms such as goal setting and project plans are seen by project managers to be so self-evident that they are no longer perceived as control mechanisms but a fundamental part of the natural work environment. Other plausible explanations of the manifestation of self control can be drawn from contextual factors such as project members' personalities and the climate of the projects (e.g. the apparent "shared destiny" involved in the MGMP arrangement for the parties in Project Beta). Taken together, the coexistence of seemingly incompatible control modes as the findings suggests is, however, instructive and provides preliminary validation to the recent findings of Lambe et al (2009) that control and self-management do play a complementary role in impacting behaviours in teams.

The analyses also show that the mechanisms through which control modes are exercised are not necessarily transferable from project to project or team to team. This is evident from the team and project specific control mechanisms used to exercise the different control modes. Even where similar control mechanisms exist in different teams or projects, they tend to be exercised quite differently. This is not surprising given that every project is unique, thus, requiring the design and implementation of control mechanisms that best meets its peculiar needs. This is evident in the use of priced bills of quantities, for example. The findings further show that more behaviourbased, outcome-based and clan controls are exercised in contractor teams than in consultant and client related teams. Being the agent, (c.f. Eisenhardt, 1985), the contractor is typically a target of formal and clan controls from a myriad of sources. Incidentally, more self-control mechanisms manifested in Contra-Beta, a contractor's 
team, than in any other team across the two projects and supports Nieminen and Lehtonen (2008) recent conclusion that "a high level of control in one mode does not require the level of other modes to be low" (2008, p. 71). Indeed, as in this study, they found that the level of self-control can be high even in circumstances where there are high levels of bureaucratic and clan control modes, especially where there is coherence and no obvious conflict among the control modes.

\section{CONCLUSION AND IMPLICATIONS}

Recent empirical developments in organizational and management literature provide a coherent theory of control that fully accounts for the range of manifestations of control in five construction project management teams involved in two ongoing construction projects in Hong Kong. A portfolio of control modes is exercised in project teams in which formal and informal control mechanisms are combined. While formal controls remain the primary form of control, they are often inadequate in dealing fully with the evolving nature of the project environment as they can become static or redundant. Informal control modes appear to provide a means of augmenting these inadequacies in a complementary manner.

Taken together, these findings make significant contribution to theory and practice with implications worth highlighting. In accord with recent empirical work on control in project and programme teams (e.g. Badenfelt, 2007, Langfield-Smith, 2008, Nieminen and Lehtonen, 2008), this study advances control theory by providing preliminary validation to a four modes of control framework that offers greater insight into the manifestations of control in project teams and the mechanisms employed in the exercise of different modes of control. This therefore suggests that a broader and holistic view on control is required in project teams that is inclusive of the 
contributions of all stakeholders to project control. Such a focus should extend beyond the implementation of formal control modes and mechanisms by stakeholders to embrace the capacity of controlees to implement clan- and self-based controls. It is, however, important to caution against "groupthink", a common consequence of high socialisation and cohesion in groups (c.f. Neck and Manz, 1994, Turner and Pratkanis, 1998), in the use of or reliance on clan controls where the collective pattern of thinking and conformity pressures in the group result in ineffective decision-making and behaviours. For organizations and managers, the evidence of a portfolio of control this study provides, however, presents opportunities for more effectively controlling projects in a manner that accounts for the dynamic nature of the project environment. Thus, to effectively control projects, it is not a choice between formal and informal control but a question of how to foster a cohesive and coherent blend of both modes of control to maximize complementarity. Organizations and their leaders must therefore recognise that the control of projects is not only a function of what formal control mechanisms stakeholders put in place, but what informal control mechanisms those being controlled also put in place to augment the inadequacies of formal control. The lack of manifestation of self control in all teams and the fact that self control manifested more in some teams than others (e.g. in Contra-Beta and Consul-Alpha than in Dual-Beta and Contra-Alpha) is also instructive. That, the lack of self-control in Client-Alpha is in part attributable to the apathetic attitude of some team members suggests that not all individuals are comfortable with self-control, resonating a similar finding by Greasley et al (2008) regarding empowerment. The acceptance of selfcontrol may therefore require greater nurturing of the target individuals and teams through the creation of more supportive organizational environments. 
However, since generalisation of the findings in the case studies to other settings is limited, the opportunity to test the four modes of control model and indeed, the notion of a portfolio of control, in a variety of contexts is a fertile avenue for other researchers. Future studies may also focus on exploring the drivers and consequences of the different modes of control as well as the strategies required in implementing a coherent portfolio of control modes in project teams.

\section{REFERENCES}

ADLER, P. S. \& BORYS, B. (1996) Two types of bureaucracy: Enabling and coercive. Administrative Science Quarterly, 41 (1), 61-89.

ARGYRIS, C. (1998) Empowerment: The emperor's new clothes. Harvard Business Review, 76 (3), 98-105.

BADENFELT, U. (2007) Trust and control in the early phases of target cost contracts. IN BOYD, D. (Ed.) Proceedings of the 23rd ARCOM Annual Conference 2007. Belfast, Northern Ireland, Association of Researchers in Construction Management, pp. 23-32.

BRYMAN, A., BRESNEN, M., BEARDSWORTH, A. D., FORD, J. \& KEIL, E. T. (1987) The concept of the temporary system: The case of the construction project. IN DI THOMASO, N. \& BACHARACH, S. (Eds.) Research in the sociology of organizations. JAI Press, Greenwich, pp. 253-283.

BUTTERFIELD, L. D., BORGEN, W. A., AMUNDSON, N. E. \& MAGLIO, A.-S. T. (2005) Fifty years of the critical incident technique: 1954-2004 and beyond. Qualitative Research, 5 (4), 475-497. 
CICMIL, S. \& HODGSON, D. (2006) New possibilities for project management theory: A critical engagement. Project Management Journal, 37 (3), 111-122.

DAINTY, A. R. J., BRYMAN, A. \& PRICE, A. D. F. (2002) Empowerment within the UK construction sector. Leadership and Organization Development Journal, 23 (5/6), 333-342.

DEWETTINCK, K. \& BUYENS, D. (2006) Linking behavioural control to frontline employee commitment and performance: a test of two alternative explanations using motivation theories. Vlerick Leuven Gent Working Paper Series. Ghent University, Vlerick Leuven Gent Management School.

EISENHARDT, K. M. (1985) Control: Organizational and economic approaches. Management Science, 31 (2), 134-149.

FLAMHOLTZ, E. G., DAS, T. K. \& TSUI, A. (1985) Toward an integrative framework of organizational control. Accounting, Organizations and Society, 10 (1), 35-50.

FLANAGAN, J. C. (1954) The critical incident technique. Psychological Bulletin, 51 (4), 327-358.

FOURNIER, V. \& GREY, C. (2000) At the critical moment: Conditions and prospects for critical management studies. Human Relations, 53 (1), 7-32.

GREASLEY, K., BRYMAN, A., DAINTY, A., PRICE, A. \& SOETANTO, R. (2008) Understanding empowerment from an employee perspective: What does it mean and do they want it? Team Performance Management, 14 (1/2), 39-55.

GREASLEY, K., BRYMAN, A., DAINTY, A. R. J., PRICE, A. D. F., SOETANTO, R. \& KING, N. (2005) Employee perceptions of empowerment. Employee Relations, 27 (4), 354-368. 
HODGSON, D. (2002) Disciplining the professional: The case of project management. Journal of Management Studies, 39 (6), 803-821.

HODGSON, D. E. (2004) Project work: The legacy of bureaucratic control in the post-bureaucratic organization. Organization, 11 (1), 81-100.

JAWORSKI, B. J. (1988) Toward a theory of marketing control: Environmental context, control types, and consequences. Journal of Marketing, 52 (3), 23-39.

KIRSCH, L. J. (1996) The management of complex tasks in organizations: Controlling the systems development process. Organization Science, 7 (1), 121.

KIRSCH, L. J. (1997) Portfolios of control modes and IS project management. Information Systems Research, 8 (3), 215-239.

LAMBE, C. J., WEBB, K. L. \& ISHIDA, C. (2009) Self-managing selling teams and team performance: The complementary roles of empowerment and control. Industrial Marketing Management, 38 (1), 5-16.

LANGFIELD-SMITH, K. (2008) The relations between transactional characteristics, trust and risk in the start-up phase of a collaborative alliance. Management Accounting Research, 19 (4), 344-364.

LEIFER, R. \& MILLS, P. K. (1996) An information processing approach for deciding upon control strategies and reducing control loss in emerging organizations. Journal of Management, 22 (1), 113-137.

MANGHAM, I. L. (1986) Power and performance in organizations: An exploration of executive process, Blackwell, Oxford.

MERCHANT, K. A. \& STEDE, W. A. V. D. (2007) Management control systems: Performance measurement, evaluation and incentives, 2nd Edn. Financial Times/Prentice Hall, Harlow, England. 
MILLS, P. K. \& UNGSON, G. R. (2003) Reassessing the limits of structural empowerment: Organizational constitution and trust as controls. Academy of Management Review, 28 (1), 143-153.

NECK, C. P. \& MANZ, C. C. (1994) From groupthink to teamthink: Toward the creation of constructive thought patterns in self-managing work teams. Human Relations, 47 (8), 929-952.

NEWCOMBE, R. (1996) Empowering the construction project team. International Journal of Project Management, 14 (2), 75-80.

NIEMINEN, A. \& LEHTONEN, M. (2008) Organizational control in programme teams: An empirical study in change programme context. International Journal of Project Management, 26 (1), 63-72.

OUCHI, W. G. (1979) A conceptual framework for the design of organizational control mechanisms. Management Science, 25 (9), 833-848.

RITCHIE, J. \& SPENCER, L. (1993) Qualitative data analysis for applied policy research. IN BRYMAN, A. \& BURGESS, R. (Eds.) Analyzing qualitative data. Routledge, London, pp. 173-194.

ROWLINSON, S. M., HO, T. K. K. \& PO-HUNG, Y. (1993) Leadership style of construction managers in Hong Kong. Construction Management \& Economics, 11 (6), 455-465.

SHARMA, A. (1997) Professional as agent: knowledge asymmetry in agency exchange. Academy of Management Review, 22 (3), 758-798.

SIMONS, R. (1995) Control in the age of empowerment. Harvard Business Review, 73 (2), 80-88. 
TURNER, M. E. \& PRATKANIS, A. R. (1998) Twenty-Five Years of Groupthink Theory and Research: Lessons from the Evaluation of a Theory. Organizational Behavior and Human Decision Processes, 73 (2-3), 105-115.

TUULI, M. M. (2009) Empowerment and control dynamics in project teams: A multilevel examination of the antecedents and job performance consequences, Ph.D Thesis, Department of Real Estate \& Construction, The University of Hong Kong, Hong Kong.

WALKER, A. (2002) Project management in construction, 4th Edn. Blackwell, Oxford, UK.

WOOLSEY, L. K. (1986) The critical incident technique: An innovative qualitative method of research. Canadian Journal of Counselling, 20 (4), 242-254.

YIN, R. K. (2003) Case study research: Design and methods, 3rd Edn. Sage Publications, Thousand Oaks, California. 
Table 1: Conceptual Framework of Control Modes and Control Mechanisms

\begin{tabular}{|c|c|c|c|c|}
\hline \multirow{2}{*}{ Characteristics } & \multicolumn{2}{|c|}{ Formal/Bureaucratic Control } & \multicolumn{2}{|c|}{ Informal Control } \\
\hline & Outcome-based & Behaviour-based & Clan-based & Self-based \\
\hline Focus of control & $\begin{array}{l}\text { Outcomes; } \\
\text { results }\end{array}$ & $\begin{array}{l}\text { Behaviour; } \\
\text { actions }\end{array}$ & Values, beliefs & Self-regulation \\
\hline Basis of control & $\begin{array}{l}\text { Rules, } \\
\text { surveillance }\end{array}$ & $\begin{array}{l}\text { Rules, } \\
\text { surveillance }\end{array}$ & $\begin{array}{l}\text { Shared values, shared } \\
\text { norms }\end{array}$ & Self-monitoring \\
\hline Source of control & $\begin{array}{l}\text { Organization or } \\
\text { External Parties }\end{array}$ & $\begin{array}{l}\text { Organization or } \\
\text { External Parties }\end{array}$ & $\begin{array}{l}\text { Group members, } \\
\text { associations }\end{array}$ & $\begin{array}{l}\text { Individuals, } \\
\text { groups }\end{array}$ \\
\hline $\begin{array}{l}\text { Ideal conditions } \\
\text { for use }\end{array}$ & $\begin{array}{l}\text { Task outcomes } \\
\text { are known and } \\
\text { measureable; } \\
\text { explicit link } \\
\text { exists between } \\
\text { extrinsic rewards } \\
\text { and producing } \\
\text { outcomes }\end{array}$ & $\begin{array}{l}\text { Knowledge of the } \\
\text { transformation } \\
\text { process; } \\
\text { behaviour } \\
\text { observable; } \\
\text { explicit link } \\
\text { between rewards } \\
\text { and behaviours }\end{array}$ & $\begin{array}{l}\text { Imperfect knowledge of } \\
\text { the transformation } \\
\text { process; immeasurable } \\
\text { outputs; behaviour } \\
\text { observable; rewards } \\
\text { linked to values }\end{array}$ & $\begin{array}{l}\text { Imperfect } \\
\text { knowledge of } \\
\text { transformation } \\
\text { process, } \\
\text { immeasurable } \\
\text { outputs, low } \\
\text { behaviour } \\
\text { observability }\end{array}$ \\
\hline $\begin{array}{l}\text { Examples } \\
\text { control } \\
\text { mechanisms }\end{array}$ & $\begin{array}{l}\text { Performance } \\
\text { standards, } \\
\text { targets, etc. }\end{array}$ & $\begin{array}{l}\text { Codes of conduct, } \\
\text { contracts, } \\
\text { handbooks, etc. }\end{array}$ & $\begin{array}{l}\text { Mission statement, core } \\
\text { values, peer pressure, } \\
\text { culture, norm. }\end{array}$ & $\begin{array}{l}\text { Autonomy, } \\
\text { decision-making } \\
\text { power, intrinsic } \\
\text { motivation, etc. }\end{array}$ \\
\hline
\end{tabular}

Source: Adapted from Nieminen and Lehtonen (2008).

Table 2: Classification Criteria of Control Mechanisms

\begin{tabular}{lllll}
\hline Nature & Initiator & Documentation & Evaluator & Classified Mode \\
\hline $\begin{array}{l}\text { Behaviour } \\
\text { Outcome }\end{array}$ & Principal & Formally documented & Principal & Behaviour-based \\
$\begin{array}{l}\text { Behaviour or } \\
\text { Outcome }\end{array}$ & Clan & Formally documented & Principal & Outcome-based \\
$\begin{array}{l}\text { Behaviour or } \\
\text { Outcome }\end{array}$ & Agent & Not formally documented & $\begin{array}{l}\text { Agent or Principal } \\
\text { (BUT Agent's initiative) }\end{array}$ & Self-control \\
\hline
\end{tabular}

Source: Adapted from Kirsch (1997). 
Table 3: Excerpts of the Control Modes and Control Mechanisms in the Five Teams

\begin{tabular}{|c|c|c|c|c|c|}
\hline Mode & Mechanisms & Description & Controller & Controllee & Level \\
\hline \multirow[t]{4}{*}{ Behaviour-based } & Dispute Resolution System & $\begin{array}{l}\text { Dispute Resolution Advisor, adjudication committee } \\
\text { and arbitration. }\end{array}$ & Project Team* & $\begin{array}{l}\text { Dual-Beta/ } \\
\text { Contra-Beta }\end{array}$ & \multirow{3}{*}{$\begin{array}{l}\text { Inter- } \\
\text { organization } \\
\text { Inter- } \\
\text { organization } \\
\text { Inter- } \\
\text { organization }\end{array}$} \\
\hline & Open Book Accounting & $\begin{array}{l}\text { Covers GMP packages and gives the client full access to } \\
\text { all costs information. }\end{array}$ & Client & Contra-Beta & \\
\hline & $\begin{array}{lr}\text { Electronic } & \text { Document } \\
\text { Management } & \text { System } \\
\text { (EDMS) } & \end{array}$ & $\begin{array}{l}\text { The system scans and centralises all incoming and } \\
\text { outgoing correspondences, providing a full document } \\
\text { history that can be traced and monitored. }\end{array}$ & Project Team* & $\begin{array}{l}\text { Client-Alpha/ } \\
\text { Consul-Alpha/ } \\
\text { Contra-Alpha }\end{array}$ & \\
\hline & Referable Decisions & $\begin{array}{l}\text { The Engineer requires the client's "no objection" to } \\
\text { several decisions before final approval to the contractor } \\
\text { can be given (e.g. extension of time to key days, claims } \\
\text { exceeding HK\$ } 300,000 \text {, etc.). }\end{array}$ & Client & Consul-Alpha & $\begin{array}{l}\text { Inter- } \\
\text { organization }\end{array}$ \\
\hline \multirow[t]{2}{*}{ Outcome-based } & Mock-up-Sample Wing & $\begin{array}{l}\text { All works in one floor are completed using pre- } \\
\text { approved quality of materials and standard of } \\
\text { workmanship as standard. }\end{array}$ & Client & Contra-Beta & $\begin{array}{l}\text { Inter- } \\
\text { organization }\end{array}$ \\
\hline & Project Budget & The project has a budget with a contingency sum. & Head Office** & $\begin{array}{l}\text { Dual-Beta/ } \\
\text { Contra-Beta/ } \\
\text { Client-Alpha/ } \\
\text { Consul-Alpha/ } \\
\text { Contra-Alpha }\end{array}$ & $\begin{array}{l}\text { Intra- } \\
\text { organization }\end{array}$ \\
\hline Clan-based & $\begin{array}{l}\text { Non-contractual Partnering } \\
\text { Arrangement }\end{array}$ & $\begin{array}{l}\text { A commitment to partnership to resolve problems } \\
\text { jointly is enshrined in a charter. }\end{array}$ & Project Team* & $\begin{array}{l}\text { Dual-Beta/ } \\
\text { Contra-Beta/ } \\
\text { Client-Alpha/ } \\
\text { Consul-Alpha/ } \\
\text { Contra-Alpha }\end{array}$ & $\begin{array}{l}\text { Inter- } \\
\text { organization }\end{array}$ \\
\hline \multirow[t]{3}{*}{ Self-control } & $\begin{array}{ll}\text { Design } & \text { Development } \\
\text { Workshops }\end{array}$ & $\begin{array}{l}\text { Used in an ad hoc basis to discuss contractor's proposed } \\
\text { designs and sequence of construction prior to } \\
\text { submission to Independent Checking Unit (ICU). }\end{array}$ & Project Architect & $\begin{array}{l}\text { Dual-Beta/ } \\
\text { Contra-Beta }\end{array}$ & $\begin{array}{l}\text { Inter- } \\
\text { organization }\end{array}$ \\
\hline & Six Day Cycle & $\begin{array}{l}\text { The contractor's target is to complete the building works } \\
\text { of each floor in six days. }\end{array}$ & Contra & Contra-Beta & $\begin{array}{l}\text { Intra- } \\
\text { organization }\end{array}$ \\
\hline & Secondary Filling System & $\begin{array}{l}\text { A secondary filling system on specific issues that seem } \\
\text { to recur is kept. }\end{array}$ & $\begin{array}{l}\text { Senior Resident } \\
\text { Engineer }\end{array}$ & Consul-Alpha & $\begin{array}{l}\text { Intra- } \\
\text { organization }\end{array}$ \\
\hline
\end{tabular}

Notes: *The multi-organization project team comprising all sub-teams of the participant organizations on each respective project. **The Head Office of each respective team/organization. 
Table 4: Cross-Team Comparison of Behaviour-based Control Mechanisms

\begin{tabular}{|c|c|c|c|c|c|}
\hline \multirow{2}{*}{ Control Mechanisms $^{\mathrm{a}}$} & \multicolumn{3}{|c|}{ Project Alpha } & \multicolumn{2}{|c|}{ Project Beta } \\
\hline & Client & Consul & Contra & Dual & Contra \\
\hline Complaint Walk & $\sqrt{ }$ & $\sqrt{ }$ & $\sqrt{ }$ & & \\
\hline Monthly Progress/Site Meeting & $\sqrt{ }$ & $\sqrt{ }$ & $\sqrt{ }$ & $\sqrt{ }$ & $\sqrt{ }$ \\
\hline Electronic Document Management System & $\sqrt{ }$ & $\sqrt{ }$ & $\sqrt{ }$ & & \\
\hline Technical Audits & $\sqrt{ }$ & $\sqrt{ }$ & $\sqrt{ }$ & & \\
\hline Contract & $\sqrt{ }$ & $\sqrt{ }$ & $\sqrt{ }$ & $\sqrt{ }$ & $\sqrt{ }$ \\
\hline Project Administration Handbook & $\sqrt{ }$ & $\sqrt{ }$ & & $\sqrt{ }$ & \\
\hline Reporting & $\sqrt{ }$ & & & & \\
\hline Referable Decisions & & $\sqrt{ }$ & & & \\
\hline Financial Matters Meeting & & $\sqrt{ }$ & $\sqrt{ }$ & & \\
\hline Site Diary & & $\sqrt{ }$ & $\sqrt{ }$ & & \\
\hline Monthly Progress Report & & $\sqrt{ }$ & $\sqrt{ }$ & $\sqrt{ }$ & $\sqrt{ }$ \\
\hline Nature of RSS Employment & & $\sqrt{ }$ & & & \\
\hline RSS Manual & & $\sqrt{ }$ & & & \\
\hline Correspondence Management & & $\sqrt{ }$ & & & \\
\hline Contract Staff Status of RSS & & $\sqrt{ }$ & & & \\
\hline Role Specification & & $\sqrt{ }$ & & & \\
\hline TTA Non-compliance Intervention & & $\sqrt{ }$ & $\sqrt{ }$ & & \\
\hline Consultant /Site Supervision Team & & & $\sqrt{ }$ & & $\sqrt{ }$ \\
\hline Independent Checking Engineer & & & $\sqrt{ }$ & & \\
\hline Environmental Protection Measures & & & $\sqrt{ }$ & & \\
\hline Interim Valuation and Payment & & & $\sqrt{ }$ & & $\sqrt{ }$ \\
\hline Project Programme of Works & & & $\sqrt{ }$ & & $\sqrt{ }$ \\
\hline Quality Assurance Certification & & & $\sqrt{ }$ & & \\
\hline Report on Contractor's Performance & & & $\sqrt{ }$ & & $\sqrt{ }$ \\
\hline Insurance Strategies & & & $\sqrt{ }$ & & $\sqrt{ }$ \\
\hline Quality Assurance System & & $\sqrt{ }$ & $\sqrt{ }$ & & $\sqrt{b}$ \\
\hline Safety Audit & & & $\sqrt{ }$ & & $\sqrt{ }$ \\
\hline Temporary Transport Arrangement & & & $\sqrt{ }$ & & \\
\hline Programme of Works & & & $\sqrt{ }$ & & \\
\hline Induction of New Employees & & & $\sqrt{ }$ & & \\
\hline Monthly Project JV Board/Management Meeting & & & $\sqrt{ }$ & & $\sqrt{ }$ \\
\hline Launching Girder Operating Guidelines & & & $\sqrt{ }$ & & \\
\hline Project Joint Venture Board & & & $\sqrt{ }$ & & \\
\hline Management System & & & $\sqrt{ }$ & & $\sqrt{ }$ \\
\hline Weekly Reports to Project JV Board/Head Office & & & $\sqrt{ }$ & & $\sqrt{ }$ \\
\hline Safe Behaviour Awards & & & $\sqrt{ }$ & & $\sqrt{ }$ \\
\hline Dispute Resolution System & & & & $\sqrt{ }$ & $\sqrt{ }$ \\
\hline Wage Protection Scheme & & & & & $\sqrt{ }$ \\
\hline Final Account Settlement & & & & & $\sqrt{ }$ \\
\hline Selection of Subcontractors-GMP works & & & & & $\sqrt{ }$ \\
\hline Open Book Accounting & & & & & $\sqrt{ }$ \\
\hline Gain Share Arrangement & & & & & $\sqrt{ }$ \\
\hline Handbooks and Manuals & & & & & $\sqrt{ }$ \\
\hline Selection of Subcontractors- Non-GMP works & & & & & $\sqrt{ }$ \\
\hline
\end{tabular}

Notes: ${ }^{\text {a } \mathrm{An}}$ " $\sqrt{ }$ " under any team indicates the control mechanism is used in the team.

${ }^{\mathrm{b}}$ In Contra-Beta, this is actually a clan control mechanism. Thus, this is only for comparative purposes. 


\begin{tabular}{|c|c|c|c|c|c|}
\hline \multirow{2}{*}{ Control Mechanisms ${ }^{\mathrm{a}}$} & \multicolumn{3}{|c|}{ Project Alpha } & \multicolumn{2}{|c|}{ Project Beta } \\
\hline & Client & Consul & Contra & Dual & Contra \\
\hline Approval Limits on Variation Orders & $\sqrt{ }$ & $\sqrt{ }$ & & & \\
\hline Annual Performance Appraisal & $\sqrt{ }$ & $\sqrt{ }$ & $\sqrt{ }$ & $\sqrt{ }$ & $\sqrt{ }$ \\
\hline Prevention of Substandard Works Audit/PASS & & $\sqrt{ }$ & $\sqrt{ }$ & & $\sqrt{ }$ \\
\hline Project Budget & $\sqrt{ }$ & $\sqrt{ }$ & $\sqrt{ }$ & $\sqrt{ }$ & $\sqrt{ }$ \\
\hline General and Particular Specifications & & & $\sqrt{ }$ & & $\sqrt{ }$ \\
\hline Priced Bills of Quantities & & & $\sqrt{ }$ & & $\sqrt{ }$ \\
\hline Key Dates /Sectional Completion & & & $\sqrt{ }$ & & $\sqrt{ }$ \\
\hline Maintenance/Defects Liability Period & & & $\sqrt{ }$ & & $\sqrt{ }$ \\
\hline Retention & & & $\sqrt{ }$ & & $\sqrt{ }$ \\
\hline Pay for safety & & & $\sqrt{ }$ & & $\sqrt{ }$ \\
\hline Liquidated \& Ascertained Damages Clause & & & $\sqrt{ }$ & & $\sqrt{ }$ \\
\hline Promotion and Recognition/Bonuses and Pay Rise & & & $\sqrt{ }$ & & $\sqrt{ }$ \\
\hline Cost Management System & & & $\sqrt{ }$ & & $\sqrt{ }$ \\
\hline Variations on Non-GMP Works & & & & & $\sqrt{ }$ \\
\hline Mock-up-Sample Wing & & & & & $\sqrt{ }$ \\
\hline Independent Checking Unit & & & & & $\sqrt{ }$ \\
\hline Modified GMP & & & & & $\sqrt{ }$ \\
\hline Preferential Tendering Arrangement & & & & & $\sqrt{ }$ \\
\hline Design Development Workshops & & & & $\sqrt{b}$ & $\sqrt{ }$ \\
\hline Bulk Purchasing & & & & & $\sqrt{ }$ \\
\hline Target Accident Rate Per 1000 Workers & & & & & $\sqrt{ }$ \\
\hline
\end{tabular}

Notes: "An " $\sqrt{ }$ " under any team indicates the control mechanism is used in the team.

${ }^{\mathrm{b}}$ In Dual-Beta, this is actually a self-control mechanism. Thus, this is only for comparative purposes.

Table 6: Cross-Team Comparison of Clan Control Mechanisms

\begin{tabular}{|c|c|c|c|c|c|}
\hline \multirow{2}{*}{ Control Mechanisms $^{\mathrm{a}}$} & \multicolumn{3}{|c|}{ Project Alpha } & \multicolumn{2}{|c|}{ Project Beta } \\
\hline & Client & Consul & Contra & Dual & Contra \\
\hline Non-contractual Partnering Arrangement & $\sqrt{1}$ & $\sqrt{ }$ & $\sqrt{ }$ & $\sqrt{ }$ & $\sqrt{ }$ \\
\hline Mutual Objectives/Partnering Charter & $\sqrt{ }$ & $\sqrt{ }$ & $\sqrt{ }$ & $\sqrt{ }$ & $\sqrt{ }$ \\
\hline Joint Problem Solving & $\sqrt{ }$ & $\sqrt{ }$ & $\sqrt{ }$ & $\sqrt{ }$ & $\sqrt{ }$ \\
\hline Informal Events & $\sqrt{ }$ & $\sqrt{ }$ & $\sqrt{ }$ & & $\sqrt{ }$ \\
\hline Nationality \& Culture & $\sqrt{ }$ & $\sqrt{ }$ & $\sqrt{ }$ & & \\
\hline Mission Statement/Corporate Mission & $\sqrt{ }$ & & & & $\sqrt{ }$ \\
\hline Peer Recognition \& Awards & & & $\sqrt{ }$ & & $\sqrt{ }$ \\
\hline Goal Alignment & & & $\sqrt{ }$ & & \\
\hline Identity Orientation & & & $\sqrt{ }$ & & \\
\hline Top Management Attitude & & & $\sqrt{ }$ & & \\
\hline Public Pressure & & & & $\sqrt{ }$ & $\sqrt{ }$ \\
\hline Organization Culture & $\sqrt{ }$ & & & $\sqrt{ }$ & \\
\hline Team Spirit & & & & $\sqrt{ }$ & $\sqrt{ }$ \\
\hline Selection of Project Team Members & & & & $\sqrt{ }$ & \\
\hline Certification and Memberships & & & $\sqrt{b}$ & & $\sqrt{ }$ \\
\hline Leadership & & & & & $\sqrt{ }$ \\
\hline Training & & & & & $\sqrt{ }$ \\
\hline Safety Culture & & & & & $\sqrt{ }$ \\
\hline
\end{tabular}


Table 7: Cross-Team Comparison of Self-Control Mechanisms

\begin{tabular}{|c|c|c|c|c|c|}
\hline \multirow{2}{*}{ Control Mechanisms $^{\mathrm{a}}$} & \multicolumn{3}{|c|}{ Project Alpha } & \multicolumn{2}{|c|}{ Project Beta } \\
\hline & Client & Consul & Contra & Dual & Contra \\
\hline Personal Weekly Report & & $\sqrt{ }$ & & & \\
\hline Secondary Filling System & & $\sqrt{ }$ & & & \\
\hline Tick-box Checklist & & $\sqrt{ }$ & & & \\
\hline Volunteer Trainers & & $\sqrt{ }$ & & & \\
\hline Alternative Construction Methods/Work Sequence & & & $\sqrt{ }$ & & $\sqrt{ }$ \\
\hline Design Development Workshops & & & & $\sqrt{ }$ & $\sqrt{b}$ \\
\hline Revision of Specification & & & & $\sqrt{ }$ & \\
\hline Corporate Social Responsibility (CSR) Programme & & & & & $\sqrt{ }$ \\
\hline Involvement in Design of Works & & & & & $\sqrt{ }$ \\
\hline MGMP Packages Design & & & & & $\sqrt{ }$ \\
\hline Six Day Cycle & & & & & $\sqrt{ }$ \\
\hline Safety Initiatives in Plant Operations & & & & & $\sqrt{ }$ \\
\hline
\end{tabular}

Notes: ${ }^{2} \mathrm{An}$ " $\sqrt{ }$ " under any team indicates the control mechanism is used in the team.

${ }^{\mathrm{b}}$ In Contra-Beta, this is actually a outcome-based control mechanism. Thus, this is only for comparative purposes. 